\title{
Efficacy and safety of, and patient satisfaction with, colonoscopic-administered fecal microbiota transplantation in relapsing and refractory community- and hospital-acquired Clostridium difficile infection
}

\author{
Muhammad Ali Khan $\mathrm{MD}^{1 *}$, Aijaz Ahmed Sofi MD²*, Usman Ahmad MD², Osama Alaradi MD², \\ Abdur Rahman Khan MD1, Tariq Hammad MD1, Jennifer Pratt RN², Thomas Sodeman MD², \\ William Sodeman $M^{2}$, Sehrish Kamal MD ${ }^{1}$, Ali Nawras MD²
}

\begin{abstract}
MA Khan, AA Sofi, U Ahmad, et al. Efficacy and safety of, and patient satisfaction with, colonoscopic-administered fecal microbiota transplantation in relapsing and refractory community- and hospital-acquired Clostridium difficile infection. Can J Gastroenterol Hepatol 2014;28(8):434-438.
\end{abstract}

OBJECTIVE: To report the efficacy and safety of, and patient satisfaction with, colonoscopic fecal microbiota transplantation (FMT) for community- and hospital-acquired Clostridium difficile infection (CDI). METHODS: A retrospective medical records review of patients who underwent FMT between July 1, 2012 and August 31, 2013 was conducted. A total of 22 FMTs were performed on 20 patients via colonoscopy. The patients were divided into 'community-acquired' and 'hospital-acquired' CDI. Telephone surveys were conducted to determine procedure outcome and patient satisfaction. Primary cure rate was defined as resolution of diarrhea without recurrence within three months of FMT, whereas secondary cure rate described patients who experienced resolution of diarrhea and return of normal bowel function after a second course of FMT.

RESULTS: Nine patients met the criteria for community-acquired CDI whereas 11 were categorized as hospital-acquired CDI. A female predominance in the community-acquired group (88.89\% [eight of nine]) was found $(\mathrm{P}=0.048)$. The primary cure rate was $100 \%$ (nine of nine) and $81.8 \%$ (nine of 11 patients) in community- and hospitalacquired CDI groups, respectively $(\mathrm{P}=0.189)$. Two patients in the hospital-acquired group had to undergo a repeat FMT for persistent symptomatic infection; the secondary cure rate was $100 \%$. During the six-month follow-up, all patients were extremely satisfied with the procedure and no complications or adverse events were reported. CONCLUSION: FMT was a highly successful and very acceptable treatment modality for treating both community- and hospitalacquired CDI.

Key Words: Clostridium difficile infection; Community-acquired; Fecal microbiota transplantation; Hospital-acquired

Clostridium difficile infection (CDI) was initially believed to be a nosocomial infection associated with the use of antibiotics. However, recent epidemiological studies have shown CDI to be an increasingly common cause of community-acquired infectious diarrhea. Additionally, the conventional risk factors associated with CDI, such as old age, comorbid conditions and previous use of antibiotics, are less common in cases acquired outside of hospital settings (1). As a result of these observations, the Infectious Diseases Society
L'efficacité et l'innocuité de la transplantation de microbiote fécal par coloscopie et la satisfaction des patients à cet égard en cas d'infection à Clostridium difficile récurrente ou réfractaire d'origine nosocomiale ou non nosocomiale

OBJECTIF : Rendre compte de l'efficacité et de l'innocuité de la transplantation de microbiote fécal (TMF) par coloscopie et la satisfaction des patients à cet égard en cas d'infection à Clostridium difficile (ICD) d'origine nosocomiale ou non nosocomiale.

MÉTHODOLOGIE : Les chercheurs ont effectué une analyse rétrospective des dossiers médicaux des patients qui ont subi une TMF entre

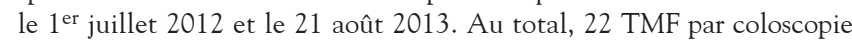
ont été effectuées chez 20 patients, divisés en ICD « d'origine non nosocomiale » et « d'origine nosocomiale ». Des sondages téléphoniques ont été effectués pour déterminer le résultat de l'intervention et la satisfaction des patients. Le taux de guérison primaire était défini comme la résolution de la diarrhée sans récurrence dans les trois mois suivant la TMF, tandis que le taux de guérison secondaire incluait les patients dont la diarrhée se résorbait et la fonction intestinale reprenait après une deuxième TMF.

RÉSULTATS : Neuf patients respectaient les critères d'ICD d'origine non nosocomiale et 11 , ceux d'origine nosocomiale. Il y avait prédominance de femmes dans le groupe d'infection d'origine non nosocomiale $(88,89 \%$ [huit sur neuf]) $(\mathrm{P}=0,048)$. Le taux de guérison primaire s'élevait à $100 \%$ (neuf sur neuf) et à $81,8 \%$ (neuf sur 11 ) dans les groupes d'origine non nosocomiale et nosocomiale, respectivement $(\mathrm{P}=0,189)$. Deux patients du groupe d'ICD d'origine nosocomiale ont dû subir une deuxième TMF en raison d'une infection symptomatique persistante, mais le taux de guérison secondaire s'élevait à $100 \%$. Pendant la période de suivi de six mois, tous les patients étaient extrêmement satisfaits de l'intervention. Aucune complication et aucun effet secondaire n'ont été déclarés.

CONCLUSION : La TMF était une modalité thérapeutique très acceptable et fructueuse des ICD d'origine nosocomiale et non nosocomiale.

of America proposed a classification of CDI as 'community-acquired' if symptoms occur in the community or within $48 \mathrm{~h}$ of admission to a hospital, after no hospitalization in the past 12 weeks. The term 'hospital-acquired' CDI was used if onset of symptoms occured $>48 \mathrm{~h}$ after admission to or $<4$ weeks after discharge from a health care facility; or indeterminate if symptom onset occurs in the community between four and 12 weeks after discharge from a hospital (2). Further studies assessing the outcome of treatment showed that

*Authors who contributed equally to the manuscript

${ }^{1}$ Department of Internal Medicine; ${ }^{2}$ Department of Internal Medicine, Division of Gastroenterology, University of Toledo Medical Center, Toledo, Ohio, USA

Correspondence: Dr Ali Nawras, Department of Internal Medicine, Division of Gastroenterology, University of Toledo Medical Center, 3000 Arlington

Avenue, Ruppert Health Center, Room 007 C, Toledo, Ohio 43614, USA. Telephone 419-383-3491, fax 419-383-6197,

e-mail ali.nawras@utoledo.edu oraijazasofi@yahoo.co.uk

Received for publication February 14, 2014. Accepted June 9, 2014 
community-acquired CDI can be associated with complications and poor outcome including recurrence (3).

The majority of CDI cases are effectively treated with oral metronidazole or vancomycin. However, the overall risk of relapse after conventional therapy can range from $20 \%$ to $30 \%$ (4). One recent study (3) reported a recurrence rate of $28 \%$ in communityacquired CDI. Following one relapse, the risk of additional relapses can be as high as $65 \%(5)$. These recurrences are treated with prolonged courses of vancomycin or fidoxomicin with some success. In recent years, there has been a great deal of enthusiasm for fecal microbiota transplantation (FMT) for the treatment of patients with recurrent CDI. Multiple systematic reviews and one recent controlled study have shown FMT to be a highly effective method of treatment for recurrent $\mathrm{CDI}(5,6)$. Currently, data regarding the treatment outcome of FMT in community-acquired versus hospital-acquired CDI are lacking. We began performing FMT in patients with CDI at our institution in July 2012. In the present study, we attempted to investigate the efficacy and safety of, and patient satisfaction with, colonoscopic methods of delivery of FMT. In addition, we evaluated the difference in patient demographics, charactersitics and treatment outcome with FMT in patients with community-acquired and hospital-acquired recurrent CDI.

\section{METHODS}

Patients

A retrospective medical record review of all patients who underwent FMT for CDI at the authors' institution between July 1, 2012 and August 31, 2013 was performed. Patients who underwent FMT $<6$ months before data gathering were excluded. Patients were divided into two categories - community-acquired and hospital-acquired CDI - as per the definitions provided by the Infectious Diseases Society of America (2). The data collected on baseline characteristics in both groups were divided into the following categories: patient characteristics, index infections, antibiotic courses for CDI and donor relationship. As a part of the protocol followed at the authors' institution, clinical outcome following FMT was obtained during follow-up outpatient visit or by contact via telephone. Telephone surveys were conducted later, as part of the present study, to determine procedure outcome and patient satisfaction. Time between FMT and telephone survey ranged between six and 18 months' duration. The telephone survey is presented in Appendix 1.

\section{Donor screening and FMT protocol}

Suitable stool donors were individuals who had not undergone antibiotic therapy for any cause for three months before stool donation and who did not have any active gastrointestinal symptoms such as diarrhea, constipation, abdominal pain, bloating, nausea or vomiting. Stool and serum tests (Table 1) were performed in all potential donors unless the donor was a spouse or significant other, in which case only stool screening tests were performed.

All FMT procedures were performed via colonoscopic route. Patients were advised to discontinue antibiotic treatment $48 \mathrm{~h}$ before the procedure. Colonic lavage (ingestion of $4 \mathrm{~L}$ of polyethylene glycol solution) was given to all patients the day before the procedure. Donors were given standard stool collection kits; stool samples were obtained within $30 \mathrm{~min}$ before performing FMT. Fifty grams of donor stool was mixed with $200 \mathrm{~mL}$ of normal saline in a blender until liquefied to milkshake consistency and was then aspirated into a $60 \mathrm{~mL}$ syringe and injected via the biopsy channel of the colonoscope into the cecum and ascending colon.

The primary cure rate was defined as resolution of diarrhea without recurrence of symptoms (as documented during the follow-up) within three months of FMT, whereas the secondary cure rate highlighted patients with resolution of diarrhea and return of normal bowel function after a second course of FMT. Treatment failure was defined as recurrence of diarrhea ( $\geq 3$ loose stools) with positive $\mathrm{C}$ difficile polymerase chain reaction stool test.

The present study was approved by the University of Toledo Institutional Review Board (Toledo, Ohio, USA).
TABLE 1

Donor screening

Stool tests
- Clostridium difficile toxin polymerase chain reaction
- Bacterial culture (enteric pathogens)
- Ova and parasites
- Cryptosporidium antigen
- Microspora
Serum tests

erum tests

- Hepatitis A immunoglobulin (lg) M

- Hepatitis B surface antigen

- Hepatitis B core antibodies (IgM and IgG)

- Hepatitis $C$ antibody

- HIV 1 and 2 antibodies

- Human T lymphotropic virus antibody

- Helicobacter pylori antibody

Rapid plasma reagin or syphillis enzyme immunoassay

\section{Statistical analysis}

Continuous variables were expressed as mean \pm SD and qualitative data were expressed as percentages. Differences between groups were evaluated using unpaired $t$ tests; $\mathrm{P}<0.05$ was considered to be statistically significant. The effect of FMT was evaluated in terms of diarrhea, abdominal pain, nausea and fatigue between the hospital- and community-acquired CDI groups before and after FMT. Statistical analysis was performed using SPSS version 20.0 (IBM Corporation, USA).

\section{RESULTS}

A total of 22 FMT procedures were performed on 20 patients via colonoscopic route, of which only three were performed in an inpatient setting. Of the 20 patients included in the study, nine met the criteria for community-acquired CDI and 11 were categorized as hospital-acquired CDI. Patient demographic data are summarized in Table 2. Baseline characteristics revealed a female predominance in the community-acquired group (Table 2). There was no difference in the mean age, duration of CDI before FMT and use of proton-pump inhibitors between community-acquired and hospital-acquired CDI (Table 1). Fluoroquinolone was the most common previously used antibiotic in hospital-acquired CDI (55\%) compared with communityacquired CDI patients, in whom clindamycin $(33 \%)$ and $\beta$-lactam antibiotics (44\%) were commonly used before the onset of symptoms.

\section{Pre- and post-FMT data analysis}

Four symptom outcomes were evaluated in the present study: diarrhea, abdominal pain, nausea and fatigue. Table 3 highlights the aforementioned clinical features of pre- and post-FMT. The mean number of days for return of normal bowel function was similar in community-acquired (4.5 days) and hospital-acquired (4.45 days) groups $(\mathrm{P}=0.328)$. Prophylactic oral metronidazole was given concomitantly to any patient in either group who had to use antibiotic for any infection other than CDI. In the community-acquired CDI group, the primary cure rate was $100 \%$. There were no relapses of CDI following FMT in any of the patients during the six-month followup. During the six-month post-FMT follow-up, three patients used antibiotics for infections other than CDI. On the other hand, in the hospital-acquired group, the primary cure rate was $82 \%$. A repeat FMT procedure was performed in two $(18 \%)$ nonresponders in this group. One experienced persistent diarrhea and developed toxic megacolon; a repeat colonoscopy with FMT was performed seven days after the initial one, following which his diarrhea resolved over the next three days. The second patient had a history of microscopic colitis and her diarrhea (CDI) recurred after using amoxicillin and clavulanic acid for a dental procedure, despite being on prophylactic metronidazole, and stools for $\mathrm{C}$ difficile were positive according to polymerase chain reaction. FMT was repeated 78 days after the initial FMT and the diarrhea 
TABLE 2

Demographics and characteristics in community- and hospital-acquired Clostridium difficile infection (CDI)

\begin{tabular}{|c|c|c|c|}
\hline \multirow[b]{2}{*}{$\begin{array}{l}\text { Demographic or } \\
\text { characteristic }\end{array}$} & \multicolumn{2}{|c|}{ CDI } & \multirow[b]{2}{*}{$\mathbf{P}$} \\
\hline & $\begin{array}{c}\text { Community } \\
\text { acquired } \\
(n=9[45 \%])\end{array}$ & $\begin{array}{c}\text { Hospital } \\
\text { acquired } \\
(n=11[55 \%])\end{array}$ & \\
\hline Age, years, mean \pm SD & $64 \pm 10.26$ & $68.27 \pm 17.88$ & 0.361 \\
\hline Female sex & $8(88.9)$ & $5(45.5)$ & 0.048 \\
\hline $\begin{array}{l}\text { Duration of symptoms, } \\
\text { months, median }\end{array}$ & 7 & 5 & 0.169 \\
\hline \multicolumn{4}{|l|}{ Index infection } \\
\hline Pneumonia & $0(0)$ & $4(36)$ & \\
\hline Urinary tract infection & $3(33)$ & $5(45)$ & \\
\hline Cellulitis & $3(33)$ & $0(0)$ & \\
\hline Dental infection & $2(22)$ & $0(0)$ & \\
\hline Osteomyelitis & $0(0)$ & $1(9)$ & \\
\hline Sepsis & $0(0)$ & $1(9)$ & \\
\hline No infection & $1(11)$ & $0(0)$ & \\
\hline $\mathrm{PPI}$ and $\mathrm{H}_{2}$ blocker use & $6(67)$ & $7(64)$ & 0.647 \\
\hline Episodes of CDI, $n$, mean & 5.6 & 4.6 & 0.175 \\
\hline \multicolumn{4}{|c|}{ Courses of metronidazole before FMT, $n$} \\
\hline 1 & $1(11)$ & $0(0)$ & 1.0 \\
\hline 2 & $1(11)$ & $6(55)$ & 0.26 \\
\hline 3 & $7(78)$ & $5(45)$ & 0.15 \\
\hline \multicolumn{4}{|c|}{ Courses of vancomycin before FMT, $n$} \\
\hline 1 & $2(22)$ & $0(0)$ & 1.0 \\
\hline 2 & $5(55)$ & $7(64)$ & 0.108 \\
\hline 3 & $2(22)$ & $2(18)$ & 0.214 \\
\hline Pulsed therapy & $0(0)$ & $2(18)$ & 1.0 \\
\hline Fidaxomicin & $3(33)$ & $6(55)$ & 0.355 \\
\hline \multicolumn{4}{|l|}{ Donor relationship } \\
\hline Spouse or partner & $2(22)$ & $3(27)$ & 0.8 \\
\hline First-degree relative & $7(78)$ & $7(64)$ & 0.5 \\
\hline Nonrelative & $0(0)$ & $1(9)$ & 0.36 \\
\hline
\end{tabular}

Data presented as $n(\%)$ unless otherwise indicated. FMT Fecal microbiota transplantation; PPI Proton pump inhibitor

resolved within two days. The patient did not report recurrence of symptoms during the six-month follow-up after second FMT. The secondary cure rate was $100 \%$. There was no association between donor relationship and the treatment outcome.

Overall, 16 of $20(80 \%)$ patients preferred stool donation from a relative. During the post-FMT survey, all patients indicated that they would recommend FMT to other patients with recurrent CDI.

\section{DISCUSSION}

$\mathrm{CDI}$ is no longer considered to be exclusively a nosocomial infection. Recent studies have shown that community-acquired CDI can be associated with severe outcomes (3). Therefore, it is imperative to understand the differences in treatment outcome between hospitalacquired and community-acquired CDI. In the present study, we observed a cure rate of $100 \%$ with FMT during a follow-up of six months in patients with community-acquired CDI compared with only $82 \%$ with hospital-acquired CDI. Symptom resolution following FMT was similar in community-acquired and hospital-acquired CDI. There were no relapses during the six-month follow-up in communityacquired CDI group.

In the present study, we also found a predominance of females in community-acquired CDI, which is supported by some earlier studies (7). Close contact with children $<2$ years of age has been identified as a risk factor for community-acquired CDI (8). A few other studies have shown infants to be carriers for several toxicogenic and nontoxicogenic strains of $\mathrm{C}$ difficile (9). Although infants are believed to be
TABLE 3

Comparison of clinical features between communityacquired and hospital-acquired Clostridium difficile infection (CDI), both pre- and post-fecal microbiota transplantation (FMT)

\begin{tabular}{|c|c|c|}
\hline \multirow[b]{2}{*}{ Symptoms (pre- and post FMT) } & \multicolumn{2}{|c|}{ CDI } \\
\hline & $\begin{array}{l}\text { Community } \\
\text { acquired }\end{array}$ & $\begin{array}{l}\text { Hospital } \\
\text { acquired }\end{array}$ \\
\hline \multicolumn{3}{|l|}{ Mild diarrhea (3-6/day) } \\
\hline Pre-FMT & 1 & 0 \\
\hline 3 days post-FMT & 2 & 0 \\
\hline 3 months post-FMT & 0 & 1 \\
\hline 6 months post-FMT & 0 & 0 \\
\hline \multicolumn{3}{|l|}{ Moderate diarrhea (7-10/day) } \\
\hline Pre-FMT & 4 & 4 \\
\hline 3 days post-FMT & 0 & 1 \\
\hline 3 months post-FMT & 0 & 0 \\
\hline 6 months post-FMT & 0 & 0 \\
\hline \multicolumn{3}{|l|}{ Severe diarrhea (>10/day) } \\
\hline Pre-FMT & 1 & 5 \\
\hline 3 days post-FMT & 0 & 0 \\
\hline 3 months post-FMT & 0 & 0 \\
\hline 6 months post-FMT & 0 & 0 \\
\hline \multicolumn{3}{|l|}{ Fatigue } \\
\hline Pre-FMT & 9 & 6 \\
\hline 3 days post-FMT & 9 & 4 \\
\hline 3 months post-FMT & 0 & 0 \\
\hline 6 months post-FMT & 0 & 0 \\
\hline \multicolumn{3}{|l|}{ Nausea } \\
\hline Pre-FMT & 3 & 5 \\
\hline 3 days post-FMT & 0 & 2 \\
\hline 3 months post-FMT & 0 & 0 \\
\hline 6 months post-FMT & 0 & 0 \\
\hline \multicolumn{3}{|l|}{ Abdominal pain } \\
\hline Pre-FMT & 2 & 5 \\
\hline 3 days post-FMT & 0 & 3 \\
\hline 3 months post-FMT & 0 & 0 \\
\hline 6 months post-FMT & 0 & 0 \\
\hline
\end{tabular}

Data presented as $n$

protected from the infection due to lack of receptors for $\mathrm{C}$ difficile in the immature colon (10), the same does not hold true for mothers who are frequently exposed to infant stools during diaper change. Therefore, this may explain the high incidence of community-acquired CDI in women.

Primary cure rates with FMT were slightly better, although they did not reach statistical significance in community- compared with hospitalacquired CDI in the present study (Table 4). An explanation for this observation needs to be explored in future studies. Among other yet unknown factors, the presence of other comorbid factors in the hospitalacquired group may be contributory to the slightly lower response observed in the present study. Additionally, infection relapse after successful FMT occurred in hospital-acquired CDI group following exposure to antibiotics in two of three patients compared with zero of three patients in community-acquired CDI. More data are needed to confirm these potential differences in the treatment outcomes between community-acquired and hospital-acquired CDI.

Limitations to the present study were its small sample size, retrospective nature and, therefore, potential for bias. There is a need for controlled studies to examine the differences in short- and long-term outcome of treatment with FMT in patients with community-acquired and hospital-acquired CDI. 
TABLE 4

Comparison of clinical outcomes post-fecal microbiota transplantation (FMT)

\begin{tabular}{lccc}
\hline & \multicolumn{2}{c}{$\begin{array}{c}\text { Clostridium difficile infection } \\
\text { (CDI) }\end{array}$} \\
\cline { 2 - 3 } Clinical outcomes post-FMT & $\begin{array}{c}\text { Community- } \\
\text { acquired (n=9) }\end{array}$ & $\begin{array}{c}\text { Hospital- } \\
\text { acquired }(\mathbf{n = 1 1 )}\end{array}$ & $\mathbf{P}$ \\
\hline Primary cure rate & $9(100)$ & $9(81.8)$ & 0.189 \\
Secondary cure rate & $\mathrm{N} / \mathrm{A}$ & $2(100)$ & \\
Relapsed or unresolved CDI & $0(0)$ & $2(18.2)$ & \\
Antibiotic use post-FMT & $3(33)$ & $3(27)$ \\
for infection other than CDI & & & \\
\hline
\end{tabular}

Data presented as $n$ (\%) unless otherwise indicated

The efficacy of FMT for treatment of recurrent communityacquired CDI is similar to hospital-acquired CDI.

DISCLOSURES: The authors have no financial disclosures or conflicts of interest to declare.

\section{APPENDIX I}

Questionnaire

Patient's date of birth:

Gender:

Questions pertaining to period before undergoing fecal microbiota transplant.

Q1. What was the time duration between diagnosis of $\mathrm{C}$ diff (Clostridium difficile) and FMT?

A1. (months)

Q2. When you were first diagnosed with $\mathrm{C}$ diff, had you taken any antibiotic for any other infection?

A2. Yes / No

Q3. If yes, what was the name of antibiotic and what was the infection?

A3.

Q4. Before FMT how was your C diff treated? Please name antibiotics and number of courses.

A4.

Q5. Were you taking any acid suppressive medication like PPI or $\mathrm{H}_{2}$ inhibitors?

A5. Yes / No

Q6. What was the severity of diarrhea? (Select one)

A6. (i) $\leq 3$ stools per day

(ii) 4-6 stools per day

(iii) $7-10$ stools per day

(iv) $>10$ stools per day

Q7. Did you have abdominal pain during $\mathrm{C}$ diff infection?

A7. Yes / No

Q8. Did you have nausea during $\mathrm{C}$ diff?

A8. Yes / No

Q9. Did you have fatigue during $\mathrm{C}$ diff infection?

A9. Yes / No

Questions pertaining to fecal transplant and immediate follow-up (3 days)

Q1. Was the fecal donor related to you? (Select one)

A1. (i) Spouse / partner

(ii) First-degree relative (parent, child)

(iii) Nonrelative

Q2. What was the number of days for normal bowel function to A2. return post FMT?

Q3. What was the severity of diarrhea 3 days post FMT? (Select one)

A3. (i) $\leq 3$ stools per day
(ii) 4-6 stools per day
(iii) $7-10$ stools per day
(iv) $>10$ stools per day

Q4. If you had abdominal pain prior to FMT, did you continue to have it 3 days after FMT?

A4. Yes / No

Q5. If you had nausea prior to FMT, did you continue to have it 3 days after FMT?

A5. Yes / No

Q6. If you had fatigue prior to FMT, did you continue to have it 3 days after FMT?

A6. Yes / No

Questions pertaining to 3-month follow-up.

Q1. What was the number of bowel movements per day during 3 months following FMT?

A1. (i) $\leq 3$ stools per day

(ii) 4-6 stools per day

(iii) $7-10$ stools per day

(iv) $>10$ stools per day

Q2. Within the 3 months following FMT, have you had any abdominal pain requiring physician/ER visit?

A2. Yes/No

Q3. Within the last 3 months following FMT, have you had any nausea requiring a physician/ER visit?

A3. Yes / No

Q4. Within the last 3 months following FMT, have you had any fatigue requiring a physician/ ER visit?

A4. Yes / No

Q5. Within the 3 months following FMT, did you experience any episodes of diarrhea requiring physician/ER visit or treatment for $\mathrm{C}$ diff (metronidazole/oral vancomycin/fidaxomicin)?

A5. Yes / No

Q6. Did you use any antibiotics for any other infection during this A6. period? (Name infection and antibiotic)

Questions pertaining to 6-month follow-up.

Q1. What was the number of bowel movements per day during 6 months following FMT?

A1. (i) $\leq 3$ stools per day

(ii) 4-6 stools per day

(iii) $7-10$ stools per day

(iv) $>10$ stools per day

Q2. Within the last 6 months following FMT, have you had any abdominal pain requiring physician/ER visit?

A2. Yes/ No

Q3. Within the last 6 months following FMT, have you had any nausea requiring a physician/ER visit?

A3. Yes / No

Q4. Within the last 6 months following FMT, have you had any fatigue requiring a physician/ER visit?

A4. Yes / No

Q5. Within the 6 months following FMT, did you experience any episodes of diarrhea requiring physician/ER visit or treatment for $\mathrm{C}$ diff (metronidazole/oral vancomycin/fidaxomicin)?

A5. Yes / No

Q6. Did you use any antibiotics for any other infection during this period? (Name infection and antibiotic)

A6.

Q7. How satisfied were you with the results of the procedure? (Select one)

A7. Extremely satisfied / satisfactory / dissatisfied

Q8. This procedure can be done by a number of routes via NG tube, colonoscopy or retention enemas, out of these three which would you have preferred? (We explained all the three procedures)

A8.

Q9. Would you recommend this procedure to a family member or friend having CDI?

A9. Yes / No 


\section{Khan et al}

\section{REFERENCES}

1. Khanna S, Pardi DS, Aronson SL, et al. The epidemiology of community-acquired Clostridium difficile infection: A populationbased study. Am J Gastroenterol 2012;107:89-95.

2. McDonald LC, Coignard B, Dubberke E, et al. Recommendations for surveillance of Clostridium difficile-associated disease. Infect Control Hosp Epidemiol 2007;28:140-5.

3. Khanna S, Pardi DS, Aronson SL, Kammer PP, Baddour LM. Outcomes in community-acquired Clostridium difficile infection. Aliment Pharmacol Ther 2012;35:613-8.

4. Louie TJ, Miller MA, Mullane KM, et al. Fidaxomicin versus vancomycin for Clostridium difficile infection. $\mathrm{N}$ Engl J Med 2011;364:422-31.

5. van Nood E, Vrieze A, Nieuwdorp M, et al. Duodenal infusion of donor feces for recurrent Clostridium difficile. N Engl J Med 2013;368:407-15.
6. Sofi AA, Silverman AL, Khuder S, Garborg K, Westerink JM, Nawras A. Relationship of symptom duration and fecal bacteriotherapy in Clostridium difficile infection-pooled data analysis and a systematic review. Scand J Gastroenterol 2013;48:266-73.

7. Leffler DA, Lamont JT. Editorial: Not so nosocomial anymore: The growing threat of community-acquired Clostridium difficile. Am J Gastroenterol 2012;107:96-8.

8. Wilcox MH, Mooney L, Bendall R, Settle CD, Fawley WN. A case-control study of community-associated Clostridium difficile infection. J Antimicrob Chemother 2008;62:388-96.

9. Rousseau C, Lemee L, Le Monnier A, Poilane I, Pons JL, Collignon A. Prevalence and diversity of Clostridium difficile strains in infants. J Med Microbiol 2011;60(Pt 8):1112-8.

10. Leffler DA, Lamont JT. Treatment of Clostridium difficile-associated disease. Gastroenterology 2009;136:1899-912. 


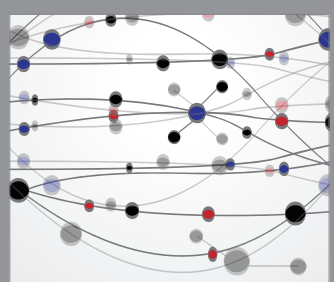

The Scientific World Journal
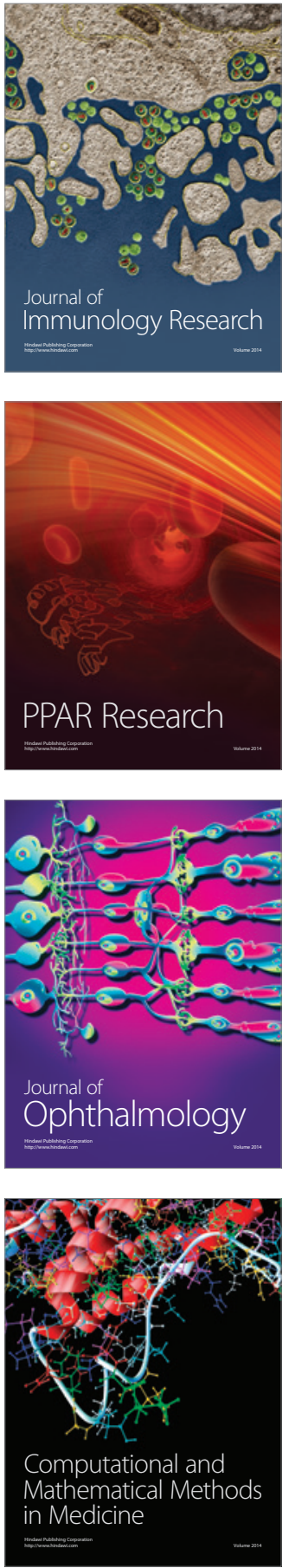

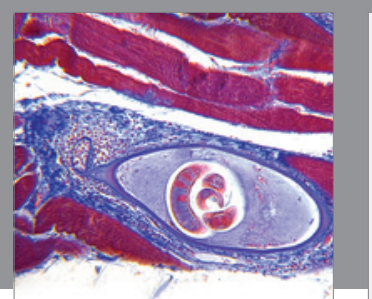

Gastroenterology Research and Practice

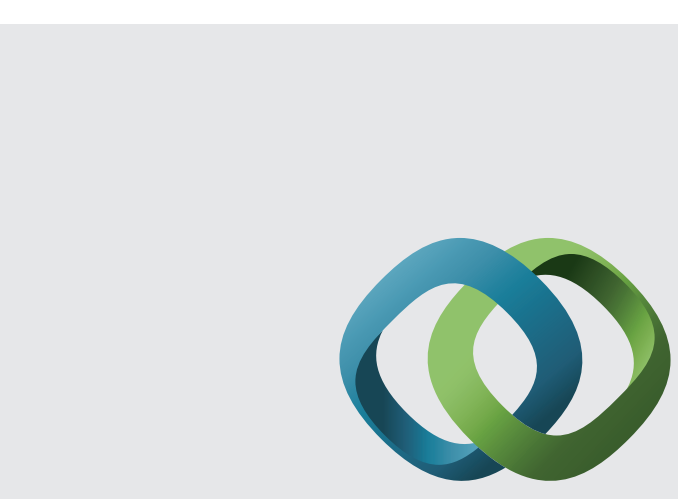

\section{Hindawi}

Submit your manuscripts at

http://www.hindawi.com
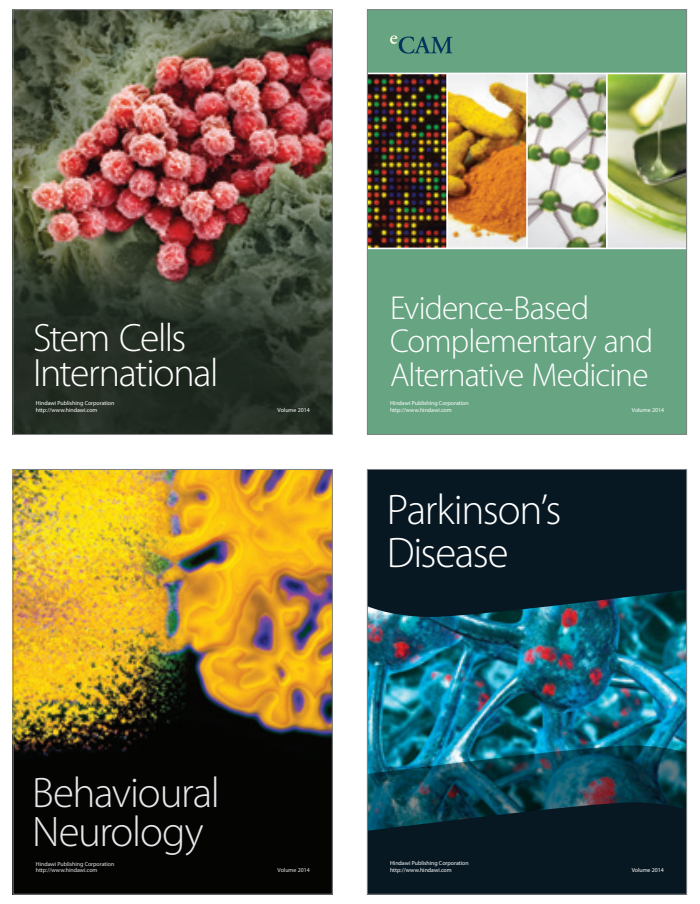
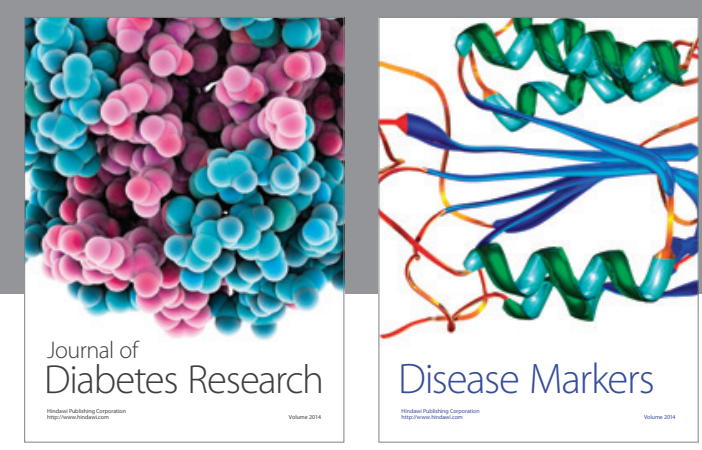

Disease Markers
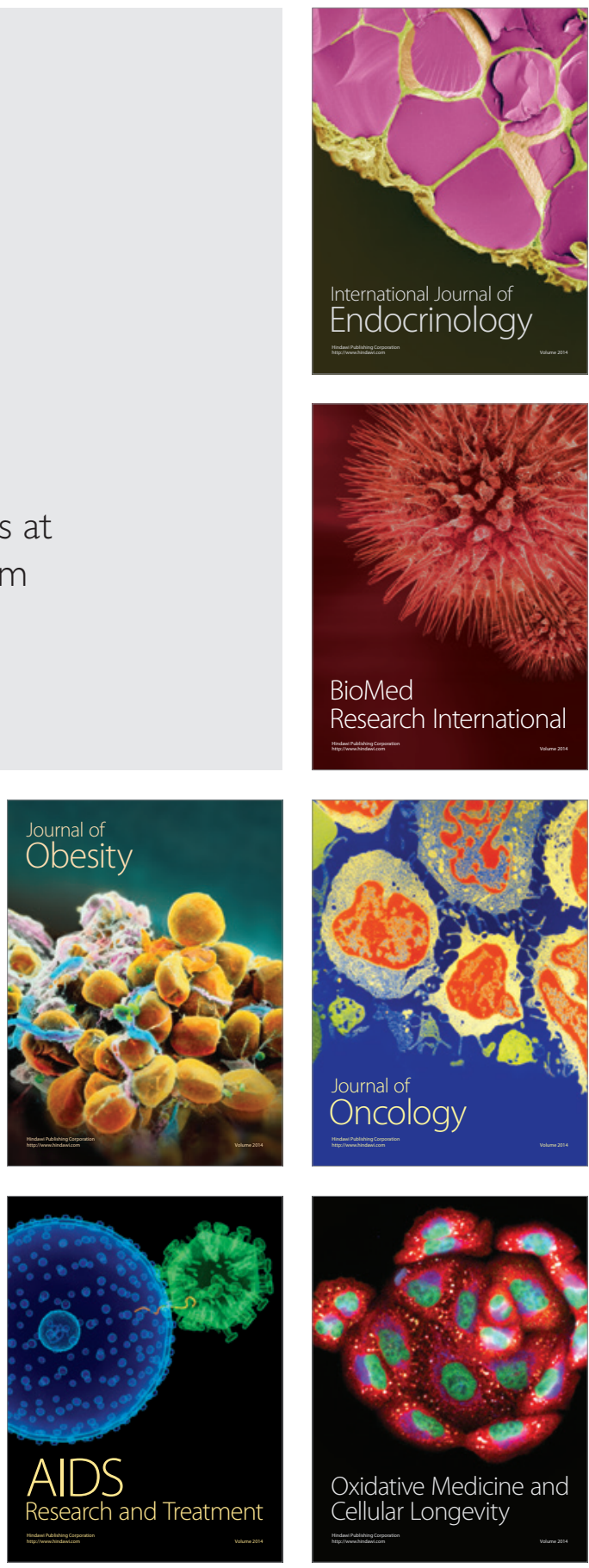